\title{
THE MEDIAL TIBIAL SYNDROME
}

\section{Exercise Ischaemia in the Medial Fascial Compartment of the Leg}

\author{
J. Puranen, Oulu, Finland \\ From the Department of Surgery, University of Oulu
}

Most runners, occasionally even joggers, complain at some time of pain over the inner border of the shin. Among athletes this complaint is known as "shin splints". The pain generally disappears within a few weeks, but the condition may also become chronic, with bouts of pain recurring over a period of several months. The pain may be so severe as to make consistent training impossible. Having excluded the possibility of stress fracture, I have labelled this condition the "medial tibial syndrome". Relief has followed treatment by operation.

\section{MATERIAL}

The series comprises eleven patients who came from different parts of Finland. Eight of these were competing athletes and three were joggers, including two women (Table I). Their average age was twenty-three years. All the patients had suffered pain for several months before operation, most of them for as long as two years. The pain had become so severe that effective training was impossible.

Clinical features and diagnosis-The site of pain was the inner border of the shin; in one

TABLE I

Details of Eleven Patients with Medial Tibial Syndrome

\begin{tabular}{|c|c|c|c|c|c|c|c|}
\hline $\begin{array}{c}\text { Case } \\
\text { number }\end{array}$ & $\begin{array}{c}\text { Age } \\
\text { (years) }\end{array}$ & Sex & Sport & Side & $\begin{array}{l}\text { Length of } \\
\text { history }\end{array}$ & $\begin{array}{l}\text { Strontium } 85 \\
\text { uptake at pain site } \\
\text { compared with } \\
\text { the control leg } \\
\text { (per cent) }\end{array}$ & Comments \\
\hline $1 *$ & 19 & Male & Pole-vaulter & Right & 2 years & Normal & \multirow{3}{*}{$\begin{array}{l}\text { No radiological sign of } \\
\text { fracture or periosteal } \\
\text { thickening }\end{array}$} \\
\hline 2 & 22 & Male & $\begin{array}{c}\text { Runner } \\
(1,500-5,000 \mathrm{~m})\end{array}$ & Left & 2 years & 250 & \\
\hline 3 & 32 & Male & Jogger & Right & 4 years & 120 & \\
\hline 4 & 27 & Male & $\begin{array}{l}\text { Hurdler } \\
(400 \mathrm{~m})\end{array}$ & Right & 6 months & Normal & \multirow{3}{*}{ Slight periosteal thickening } \\
\hline 5 & 28 & Male & $\begin{array}{c}\text { Runner } \\
(5,000-10,000 \mathrm{~m})\end{array}$ & Right & $2 \cdot 5$ years & 160 & \\
\hline 6 & 19 & Male & Jogger & Left & 2 years & Normal & \\
\hline 7 & 23 & Female & Jogger & Left & 1 year & Normal & \multirow{5}{*}{$\begin{array}{l}\text { Interval between strontium } \\
\text { counts } 3 \text { months. Slight } \\
\text { periosteal thickening at } \\
\text { pain site in left tibia }\end{array}$} \\
\hline $8^{*}$ & 26 & Male & $\begin{array}{c}\text { Runner } \\
(1,500-5,000 \mathrm{~m})\end{array}$ & $\begin{array}{c}\text { Right } \\
\text { Left }\end{array}$ & $\begin{array}{l}3 \text { years } \\
1 \text { month }\end{array}$ & $\begin{array}{l}\text { Normal } \\
130\end{array}$ & \\
\hline 9 & 22 & Male & $\begin{array}{c}\text { Runner } \\
(1,500-5,000 \mathrm{~m})\end{array}$ & Right & 1 year & Normal & \\
\hline 10 & 23 & Male & $\begin{array}{c}\text { Runner } \\
(1,500-5,000 \mathrm{~m})\end{array}$ & Left & 1.5 years & Normal & \\
\hline 11 & 15 & Female & Long jumper & Right & 9 months & Normal & \\
\hline
\end{tabular}

* Case report in the text. 
patient the pain was located in the uppermost and middle thirds, but in all the others it was in the lowest and middle thirds. The pain was typically well localised, without any radiation. The athletes recalled that pain began to appear at the end of a run, but as time went on it occurred earlier and earlier during exercise. In a milder form, the soreness was felt only during exercise, particularly in the toe-off moment. In many cases, however, the pain had become so severe that it affected walking and was sometimes felt even at rest. The most tender spot could be palpated within a fairly restricted area at the postero-medial border of the tibia. No swelling was visible. The peripheral pulses were distinct, and no neurological changes were noted.

In order to eliminate the possibility of stress fracture, several radiographs were obtained, and tomography and strontium profile counting were performed. In two patients there was thickening of the periosteum, but no suggestion of a fracture line was seen. Only four of the patients had elevated strontium uptake at the pain site compared with that in the healthy limb (Table I). In one case (Case 2 ) the strontium value was so high ( 250 per cent) that a fracture was suspected. However, there was no radiological evidence of a fracture, not even periosteal thickening. Strontium uptake in a typical tibial stress fracture is usually over 300 per cent higher than the corresponding control value.

\section{TREATMENT}

An appropriate technique of operation for patients with shin soreness resistant to conservative treatment was discovered during exploration in the first case.

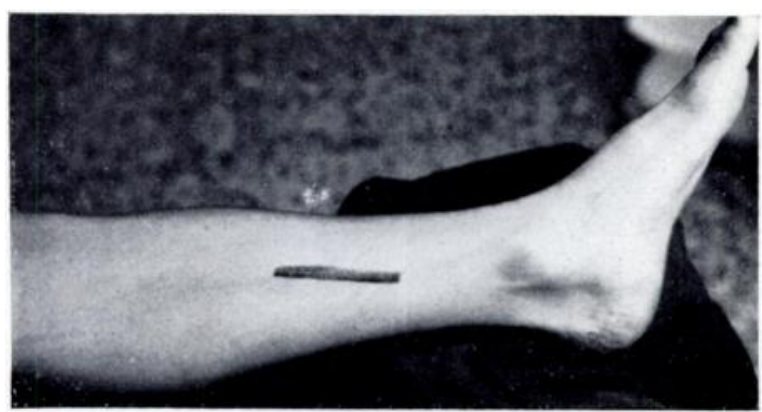

Fig. 1

Line of skin incision at the site of pain.

\section{CASE REPORT}

Case 1-A nineteen-year-old male polevaulter reported that his training season had been spoilt by pain which had persisted for several months. Rest, medication (including cortisone injections) and physiotherapy had all been ineffective. On examination there was marked tenderness over the posteromedial border of the middle and lower thirds of the shin, where unevenness was also palpable. Strontium counting revealed no pathological uptake. Radio-

graphs did not show any fracture or thickening of the periosteum. Since conservative treatment yielded no improvement, a decision was made to explore the shin. The crural fascia was incised. Nothing pathological could be seen except the apparent tension and thickening of the fascia, particularly at its site of insertion to the postero-medial edge of the tibia. A histological specimen from this site showed fibroblastic proliferation and tissuecell infiltration. After operation the pain disappeared.

Each patient of the series underwent the following operation. A skin incision was made at the site of pain along the medial border of the shin (Fig. 1). The crural fascia was thus exposed. The fascial compartment of the flexor digitorum longus, flexor hallucis longus and tibialis posterior (Fig. 2) was split near its insertion to

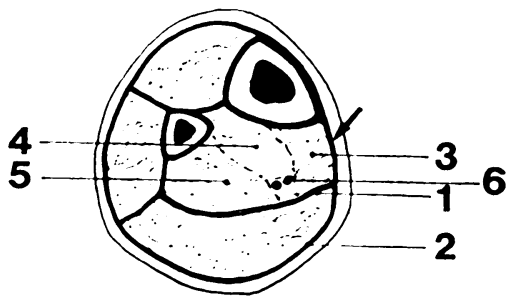

FIG. 2

Transverse section through the lowermost and middle thirds of the tibia. 1. Deep crural fascia; 2. Superficial crural fascia; 3. Flexor digitorum longus; 4. Tibialis posterior; 5. Flexor hallucis longus; 6. Posterior tibial artery and tibial nerve. Arrow indicates the site of the fascial division. 
the medial border of the tibia (Fig. 3). The division of the fascia was made long enough (usually about 10 centimetres) to ensure that the tension was released. Only the skin was closed.

The muscle appeared normal in all except Case 8, in which necrotic putty-like material was noted. Necrosis was confirmed by histological examination. In none of the cases was there anything to suggest a fracture. The fascia was examined histologically each time and it mostly showed chronic inflammatory infiltration. Only two patients lacked any fascial changes.

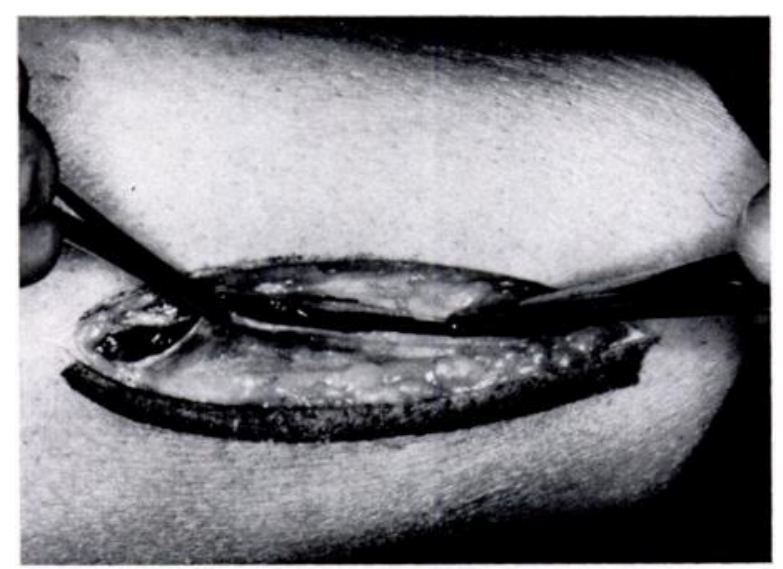

Fig. 3

The tense crural fascia has been divided near the medial margin of the tibia.

\section{RESULTS}

The operation was followed by uneventful recovery. Each patient was allowed to move during the first day after operation and to start gentle training two or three weeks later. The pain disappeared in every case, and the patients were able to begin effective training after a

month. In none of the cases has the pain recurred. The following report demonstrates how soon an athlete with severe pain recovered after fasciotomy.

\section{CASE REPORT}

Case 8-A twenty-six-year-old middle-distance runner had been suffering for three years from pain over the inner side of the right shin, which from time to time totally prevented training. Radiographs showed no sign of fracture and strontium counting was normal. Operation was planned, but it was postponed because the pain subsided. Three weeks later during exercise a pain began over the left shin, which had previously been in a perfect condition. The ache soon became so severe that walking was difficult, and pain could even be felt at rest. Radiographs showed slight periosteal thickening at the pain site, and strontium counting now revealed increased uptake. Both legs were operated upon at the same time. The fascia of each was clearly tense and thickened, and necrotic spots were visible in the left flexor digitorum longus. After fasciotomy the pain disappeared immediately, and the patient was able to start gentle training after two weeks, which was gradually increased to full training after four weeks (about 120 kilometres/week).

\section{DISCUSSION}

The pain in the medial tibial syndrome closely resembles that described by Devas (1958) in stress fracture of the tibia confined to one cortex of bone. It is therefore difficult to distinguish 
the two conditions. In the present series, however, no fractures were discernible, although periosteal thickening was noted in two cases. Strontium uptake at the pain site was increased in four cases. Only one case displayed a value so high that a fracture was suspected, but there was no radiological sign of fracture-not even periosteal thickening. Moreover, if the pain in our patients had resulted from stress fractures, division of fascia would certainly not have produced immediate recovery.

There is a closer resemblance, however, between the medial tibial syndrome and the ischaemias of the muscular compartments of the leg, such as the anterior tibial syndrome (Horn 1945, Hughes 1948, Mavor 1956, Paton 1968), the syndrome of the peroneal compartment (Edwards 1969) and ischaemia in the fascial compartment of the soleus (Kirby 1970). The anterior tibial syndrome is the best known of these. Its clinical course is usually acute and it may lead to muscle necrosis as well as motor and sensory changes. The medial tibial syndrome is mainly a matter of chronic shin soreness which interferes with training. Only once did histological examination reveal necrotic spots in the muscle.

Ischaemic pain in a muscular compartment is quite understandable, because during prolonged exercise a muscle may retain so much extracellular fluid as to increase its weight by 20 per cent, and its bulk consequently increases (Wright 1961). If the fascial wall does not yield, the disproportion between the muscle and the fascial compartment results in increased compartmental pressure. Lewis (1936) noted that a rise of 50-60 millimetres $\mathrm{Hg}$ was sufficient to occlude the fine intramuscular vessels. Hence it is the degree of muscular swelling and the distensibility of the fascial wall that determine whether pain is present and whether the condition is acute, with muscular necrosis, or chronic, with pain during exercise.

The pathogenesis of medial tibial syndrome is well explained by increased pressure in the fascial compartment of the deep flexor muscles resulting from prolonged exercise. This explanation is supported by the thickening and tension of the crural fascia noted during the operation and, above all, by the immediate disappearance of pain after fasciotomy.

\section{SUMMARY}

1. Exercise ischaemia in athletes with chronic pain over the postero-medial border of the tibia is described.

2. Fasciotomy of the compartment of the deep flexor muscles as a treatment of "shin splints" is recommended.

3. In eleven patients the symptoms were completely relieved and the athletes were able to start effective training within four weeks.

\section{REFERENCES}

Devas, M. B. (1958): Stress fractures of the tibia in athletes or "shin soreness". Journal of Bone and Joint Surgery, 40-B, 227-239.

EDWARDS, P. W. (1969): Peroneal compartment syndrome. Journal of Bone and Joint Surgery, 51-B, 123-125.

HoRN, C. E. (1945): Acute ischaemia of the anterior tibial muscle and long extensor muscles of the toes. Journal of Bone and Joint Surgery, 27, 615-622.

Hughes, J. R. (1948): Ischaemic necrosis of the anterior tibial muscles due to fatigue. Journal of Bone and Joint Surgery, 30-B, 581-594.

KIRBY, N. G. (1970): Exercise ischaemia in the fascial compartment of soleus. Journal of Bone and Joint Surgery, 52-B, 738-740.

LEWIS, T. (1936): Vascular Disorders of the Limbs, p. 36. London: Macmillan and Co. Limited.

MAvor, G. E. (1956): The anterior tibial syndrome. Journal of Bone and Joint Surgery, 38-B, 513-517.

Paton, D. F. (1968): The pathogenesis of anterior tibial syndrome. Journal of Bone and Joint Surgery, 50-B, 383-385.

Wright, S. (1961): Applied Physiology. Tenth edition, revised by C. A. Keele and E. Neil. London: Oxford University Press.

Vol. $56 \mathrm{~B}$, NO. 4, NOVEMBER 1974 